\title{
Dynamic flow analysis of current and future end-of-life vehicles generation and lead content in automobile shredder residue
}

\section{$\operatorname{AUTHOR}(S):$}

Yano, Junya; Hirai, Yasuhiro; Okamoto, Kengo; Sakai, Shin-ichi

\section{CITATION:}

Yano, Junya ...[et al]. Dynamic flow analysis of current and future end-of-life vehicles generation and lead content in automobile shredder residue. Journal of Material Cycles and Waste Management 2013, 16(1): 52-61

\section{ISSUE DATE:}

2013-07-18

URL:

http://hdl.handle.net/2433/196707

\section{RIGHT:}

The final publication is available at Springer via http://dx.doi.org/10.1007/s10163-013-0166-1 


\section{Dynamic flow analysis of current and future end-of-life vehicles generation and lead content in automobile shredder residue}

\begin{tabular}{|l|l|}
\hline Type of article & Original article \\
\hline Authors & Junya Yano, Yasuhiro Hirai, Kengo Okamoto, Shin-ichi Sakai \\
\hline $\begin{array}{l}\text { Aunya Yano } \\
\quad \text { Kyoto University Environment Preservation Research Center, Yoshida } \\
\text { Honmachi, Sakyo-ku, Kyoto 606-8501, Japan } \\
\text { Yasuhiro Hirai } \\
\quad \text { Kyoto University Environment Preservation Research Center, Yoshida } \\
\text { Honmachi, Sakyo-ku, Kyoto 606-8501, Japan } \\
\text { Kengo Okamoto } \\
\text { Cabinet Office, Government of Japan, 1-11-39, Nagatacho, Chiyoda-ku, } \\
\text { Tokyo 100-0014, Japan } \\
\text { Shin-ichi Sakai } \\
\quad \text { Kyoto University Environment Preservation Research Center, Yoshida } \\
\text { Honmachi, Sakyo-ku, Kyoto 606-8501, Japan }\end{array}$ \\
\hline E-mail address & $\begin{array}{l}\text { yano@eprc.kyoto-u.ac.jp } \\
\text { End-of-Life Vehicle (ELV), Automobile Shredder Residue (ASR), Lead, } \\
\text { Population balance model, Substance Flow Analysis }\end{array}$ \\
\hline
\end{tabular}

\section{Abstract}

Since End-of-life vehicles (ELVs) contain toxic substances, they have to be treated properly. The purpose of this study was to obtain useful information for ELVs management from the viewpoint of toxicity. We focused on lead as a representative toxic substance contained in vehicles and investigated the dynamic substance flow of lead contained in ELVs and its content in automobile shredder residue (ASR). A population balance model was used to estimate the number of ELVs generated between FY (fiscal year) 1990-2020, employing a Weibull distribution for the lifespan distribution. 16 lead-containing components of the vehicle were considered. It was estimated that the annual number of ELVs generated would be 2.9 million as of FY2020. The results implied it is hard to remove $\mathrm{Pb}$ completely. This is because $5,000-11,000 \mathrm{t}-\mathrm{Pb}$ will still remain in vehicles in use in FY2020 even though most components in new model vehicles could be replaced by lead-free alternatives. As of FY2010, the substance flow showed that Pb contained in ELVs amounted to 4,600-5,700 t-Pb. Of this, $13.2-14.0 \%$ was contained in ASR. The Pb content in ASR could be dramatically decreased by FY2020, but it will continue to contain $240-420 \mathrm{mg}-\mathrm{Pb} / \mathrm{kg}$ if the treatment system is not improved. 


\section{Introduction}

The automotive industry is one of the biggest industries in the world, as vehicles are indispensable for modern life. Unlike other used products such as home appliances and small electronic equipment, ELVs (end-of-life vehicles) can easily be monitored and collected because every owner can be identified by the vehicle registration system. Common metals (ferrous and non-ferrous) account for a high proportion of the total weight of a vehicle; ferrous and non-ferrous metals account for approximately $70-80 \%$ and $5-10 \%$ of a passenger vehicle, respectively [1]. The remaining weight consists of other materials such as plastics and rubbers. Some components contain toxic substances such as lead, mercury, and cadmium, and therefore, vehicles should be collected and treated properly at the end of their useful lifespan.

In Japan, MITI (the Ministry of International Trade and Industry, Japan) issued the "Automobile recycling initiative” in 1997 [2]. Then, JAMA (Japan Automobile Manufacturers Association, Inc.) established an action plan and revised it in 2002 considering EU Directive (2000/53/EC) [3]. One of their targets was to reduce the $\mathrm{Pb}$ content of components of passenger vehicles (except for the lead-acid battery) by more than $90 \%$ by 2006 , compared to the total content in 1996 of 1,850 g-Pb per vehicle. This target was continued after January 2006 and this progress was considered in our analysis.

Estimating the number of disposed ELVs not only in the past and present but also in the future is necessary for ELV management. A population balance model (PBM) is a dynamic estimation model that can be described basing on the mass balance between input, stock, and output of materials or products that have a lifespan. For instance, Kim et al. [4] estimated the amount of WEEE generated in the period 2000-2020 in South Korea and Polák et al. [5] estimated the number of mobile phones generated in 1990-2020 in the Czech Republic. Estimation of the flow of toxic or valuable substances contained in a product is also possible by employing a material flow analysis of the product using PBM. Tasaki et al. [6] conducted a substance flow analysis (SFA) of brominated flame retardants (BFRs), Sb, and PBDDs/DFs in components of TV sets after predicting the material flow of TV sets in the period 1995-2020. Daigo et al. [7] estimated the amount of copper and copper alloy generated from in-use stock including vehicles. They also estimated the amount of $\mathrm{Cr}$ and $\mathrm{Ni}$ in stainless steel [8].

With regard to the SFA of lead, Tukker et al. [9] conducted an SFA to analyze trends in uses and emissions of lead in the EU from 2000 to 2030. Elshkaki et al. [10] developed dynamic SFA, which combines physical and socio-economic elements to estimate lead demand and supply in different applications. They also used SFA to demonstrate that non-intentional flows of lead originating from mixed primary resource applications such as the production of zinc are larger than those originating from the waste streams of intentional applications of lead [11]. Fuse et al. [12] showed the impact of this by shifting to lead-free solders in Japan using dynamic material flow analysis. Although there 
have been some studies focused on the SFA of lead or on the elemental analysis of lead content in ASR, which will be mentioned later, few studies have applied dynamic SFA to lead contained in ELVs.

The purpose of this study was to obtain useful information for ELV management in Japan from the viewpoint of toxicity. We focused on lead as a representative toxic substance contained in vehicles and investigated the dynamic substance flow of lead contained in ELVs and its content in ASR after estimating the numbers of ELVs generated in the past, present, and future.

\section{Materials and methods}

\section{Generation of ELVs}

The dynamic generation of ELVs between FY1990 and FY2020 was estimated using PBM. Here, passenger vehicles and freight vehicles were considered, while light motor vehicles (below 660 cc displacement) were excluded owing to a lack of data. It was considered that passenger vehicles and freight vehicles were sufficient to elucidate the disposal trend of ELVs, as the number of light motor vehicles in use in Japan accounted only for $36.8 \%$ of the total number of vehicles in use at the end of FY2010 [13] [14].

PBM considers the lifespan of a vehicle and was used to estimate the number of ELVs generated. The lifespan in this study was defined as the period from the fiscal year in which the vehicle was first registered in Japan to the fiscal year when its registration was cancelled. Owing to a shortage of data, all vehicles whose registration had been cancelled were regarded as ELVs, although some vehicles were exported after the registration had been cancelled. Statistical data did not differentiate exported used vehicles from new ones until FY2001. In the estimation of the flow of Pb, export was considered only between FY2001 and FY2011.

The estimation process is depicted in Fig. 1. To estimate the number of ELVs generated, the annual number of vehicles whose first registration year, as reported by AIRIA (Automobile Inspection \& Registration Information Association) and JADA (Japan Automobile Dealers Association) [15], was between FY1973 and FY2010 was used as past data and between FY2011 and FY2020 was used as prospective future data. The annual total number of ELVs generated in FY $Y$ could be calculated by summing up the number of ELVs generated by first registration year, as shown in Eq. 1. The number of ELVs generated in FY Y, which were first registered in year $y$, was calculated by subtracting the number of vehicles in use, as shown in Eq. 2 .

$$
\begin{gathered}
N_{E L V}^{Y}=\sum_{y} N_{E L V}^{Y}(y) \\
N_{E L V}^{Y}(y)=N_{U s e}^{Y-1}(y)-N_{U s e}^{Y}(y)
\end{gathered}
$$


$N_{E L V}^{Y} \quad:$ The annual total number of ELVs generated in FY $Y$

$N_{E L V}^{Y}(\mathrm{y}) \quad$ : The number of ELVs in FY $Y$ that were first registered in year $y$ and disposed of

$N_{U s e}^{Y}(y) \quad$ : The number of vehicles in use in FY $Y$ that were first registered in year $y$

To estimate the number of vehicles in use, $N_{U s e}^{Y}(y)$, a lifespan distribution with respect to the first registration year had to be determined. A Weibull distribution, which has been frequently used in previous studies [4-8], was employed for the lifespan distribution of a vehicle. Considering that the remaining rate obtained from actual statistical data showed a sharp decrease soon after registration, a combination of two Weibull distributions with the same average lifespan were assumed: the first distribution describes the user group that tends to dispose of their vehicles relatively soon after registration and the other describes the user group without such preferences. The remaining rate function of the vehicle for the first registration year $y$ can be described by Eq. 3. It was assumed that the lifespans of different types of vehicles were not different but varied by their first registration years. Linear approximations were assumed for the shape parameter $\left(p_{y}, q_{y}\right)$, the scale parameter, and the proportion $r_{y}$ from FY1990 to FY2020 of those parameters between FY1979 to FY1994 were obtained using the maximum likelihood method, as explained below.

$$
F(y, t)=\exp \left\{-\left(\frac{t+0.5}{\eta}\right)^{\mathrm{p}_{\mathrm{y}}}\right\} \times r_{y}+\exp \left\{-\left(\frac{t+0.5}{\eta}\right)^{\mathrm{q}_{\mathrm{y}}}\right\} \times\left(1-r_{y}\right)
$$

$\begin{array}{ll}F(y, t) & : \text { Remaining rate } \\ y & : \text { First registration year } \\ t & : \text { Vehicle age } \\ p_{y}, q_{y} & : \text { Shape parameter } \\ \eta & : \text { Scale parameter } \\ r_{y} & : \text { Proportion of two distributions }\end{array}$

The discard rate $D(y \mid t)$ for a vehicle first registered in the year $y$ and disposed of at an age greater than $t$ and less than $t+1$ can be described using the remaining rate function $F(y, t)$, as shown in Eq. 4, and was expressed as $D_{t, t+1}$. Here, the probabilities $D(y \mid t=0,1,2, \cdots)$ are independent of one another. In addition, the number of ELVs first registered in year $y$ and disposed of at the age of $t$ was $N_{E L V}(y, t)$. Therefore, the likelihood of this can be described by Eq. 5 and its $\log$ likelihood function is given by Eq. 6 . Then, each parameter in $F(y, t)$ can be determined when $\mathrm{L}(\mathrm{y})$ is maximised.

$$
D(y \mid t)=\int_{t}^{t+1} F(y, t) d t=D_{t, t+1}
$$




$$
\begin{gathered}
l(y) \propto\left(D_{0,1}\right)^{N_{E L V}(y, 0)} \times\left(D_{1,2}\right)^{N_{E L V}(y, 1)} \cdots \times\left(D_{n, \infty}\right)^{N_{E L V}(y, n)} \\
L(y) \propto \sum_{t}\left\{E(y, t) \times \ln D_{t, t+1}\right\}
\end{gathered}
$$

\section{Average weight of a vehicle}

The average weight of a vehicle by its first registration year, $W a_{U s e}(y)$, was estimated to consider that the weight has tended to increase over time. AIRIA reports the number of vehicles by both first registration year and vehicle weight $[16,17]$. Using these data, the mass balance equation of the vehicles in use for each FY can be described by Eq. 7. Then, the average weight of a vehicle first registered in year $y$ between 1991 and 2009, $W a_{U s e}(y)$, was calculated. A linear approximation was applied to estimate the average weight for other years, including those in the future.

$$
W t_{U s e}^{Y}=\sum_{y}\left\{N_{U s e}^{Y}(y) \times W a_{U s e}(y)\right\}=\sum_{u}\left\{N_{U s e}^{Y}(u) \times W a_{U s e}(u)\right\}
$$

$W t_{\text {Use }}^{Y} \quad$ : Total weight of vehicles in use in FY Y

$N_{U s e}^{Y}(u) \quad$ : The number of vehicles in use in FY $Y$ categorized as $u$ on a weight basis

$W a_{U s e}(y) \quad$ : Average weight of a vehicle first registered in year $y$

$W a_{U s e}(u) \quad$ : Average weight of a vehicle categorized as $u$ on a weight basis.

\section{Pb content in ELV and ASR}

The 16 components of the new model vehicle that contained $\mathrm{Pb}$ as of 1996 were reported by JAMA. Lead-acid batteries were not included in these components because they are dealt with under another recycling scheme. JAMA and car producers have published the progress of reduction for each component based on their action plans. According to the reported information, progress was divided into three periods: no reduction, under reduction, and reduction complete (lead free). A linear reduction in $\mathrm{Pb}$ content was assumed during the reduction period. The assumed $\mathrm{Pb}$ contents in each component for every sales release year are shown in Table 1. Most components in new model vehicles sold after 2006 achieve a "lead-free” status, except for printed circuit board, other engine components, and other car components.

$\mathrm{The} \mathrm{Pb}$ content per vehicle for every first registration year was estimated using the $\mathrm{Pb}$ contents of each component in Table 1. The Pb contents of vehicles that will be sold between 2011 and 2020 
were assumed to decay exponentially. Here, not all vehicles sold as of year $y$ are new models. It is not clear whether components in vehicles sold before year $y$ are replaced with newer ones containing less $\mathrm{Pb}$. Therefore, two cases were assumed in the analysis. The first case is referred to as the "minimum case," in which it is assumed that the $\mathrm{Pb}$ content in a vehicle registered in year $y$ and started to be sold before $y$ equals the $\mathrm{Pb}$ content of the newest model in year $y$. The other case is the "maximum case," in which it is assumed that the components are not replaced with newer model ones until full model of the vehicles is started selling. It is thought that the actual $\mathrm{Pb}$ content per vehicle will be in the range of these two cases.

After usage, depending on the ELV treatment system, components containing Pb enter three streams in stages. First, some components of the ELV are dismantled and collected in the dismantling process. Then, the ELV with the remaining components is shredded and some fraction of this is recovered as resources. Finally, the remaining fractions are disposed of as ASR and treated in ASR recycling facilities. In this way, $\mathrm{Pb}$ contained in the vehicle components is partitioned into each stream. Table 2 shows the partition ratio on a weight basis.

The amounts of $\mathrm{Pb}$ contained in vehicles in use and ELVs for every first registration year were estimated by multiplying the number or weight of vehicles by the $\mathrm{Pb}$ content per vehicle. Additionally, partition ratios were multiplied to estimate the $\mathrm{Pb}$ content in collected components, recovered resources, and ASR. The total weight of ASR generated in FY Y was estimated using Eq. 8, which JAMA obtained by shredding experiment [19].

$$
W t_{A S R}^{Y}=0.1819 \times W t_{E L V}^{Y}-11.078
$$

$W t_{A S R}^{Y} \quad$ : Total weight of ASR generated in FY $Y[\mathrm{~kg}]$

$W t_{E L V}^{Y} \quad$ : Total weight of ELVs generated in FY $Y[\mathrm{~kg}]$

\section{Results and discussion}

\section{Generation of ELVs}

The estimated results with statistical data are shown in Fig. 2. The number of ELVs generated annually decreased after FY2003 while it had increased up until then. As of FY2010, 3.8 million ELVs were estimated to be generated annually, and 2.9 million were predicted to be generated in FY2020. The calculation error in each estimate against the actual statistical data between FY1990 to FY2010 seemed large, ranging between -21.3 and 35.7\%. However, the trends of ELV generation were considered to be well described because the calculation error in the estimated total numbers of ELVs against the total number of actual statistical data in these periods was $0.69 \%$. It should note that this estimated generation of ELVs includes exported ELVs. 


\section{Dynamic SFA of $\mathbf{P b}$ in vehicles}

The estimates of the amount of $\mathrm{Pb}$ potentially contained in the vehicles are shown in Fig. 3. Reductions in the $\mathrm{Pb}$ content of vehicles and the decrease in the number of vehicles in use resulted in a reduction in the net amount of $\mathrm{Pb}$. In total, a 54-69\% reduction in the $\mathrm{Pb}$ content was achieved between FY1995 and FY2010, while a 72-81\% reduction is to be expected between FY2010 and FY2020. This result shows that it is hard to remove $\mathrm{Pb}$ completely, and 5,000-11,000 t-Pb will remain in vehicles in use in FY2020, even though most components will have been replaced with lead-free alternatives.

After disposal as of an ELV, most ELVs were treated in Japan, whereas some wereexported as used vehicles. Fig. 4 shows the partitioning of Pb contained in ELVs in FY2001-2011. The reduction of $\mathrm{Pb}$ contained in ASR seemed slower than in the other streams because components containing $\mathrm{Pb}$, such as printed circuit board, tended to be partitioned to ASR. Fig. 5 shows the substance flow of $\mathrm{Pb}$ as of FY2010. Pb contained in vehicles in use and in ELVs accounted for 26,000-39,000 t-Pb (590890 g-Pb per vehicle) and 4,600-5,700 t-Pb (1,200-1,500 g-Pb per vehicle), respectively. Thus, compared to a vehicle in use, an ELV seems to contain larger amounts of Pb. This is because ELVs are older and contain more $\mathrm{Pb}$, whereas vehicles in use are newer and contain less $\mathrm{Pb}$.

The results indicated that 19.5-21.1\% of $\mathrm{Pb}$ contained in ELVs ends up in foreign countries as used vehicles. This outflow may cause pollution if they are not properly treated after usage in the countries to which they are exported. With respect to the domestic treatment stream, most $\mathrm{Pb}$ is partitioned into collected components in the dismantling process, with 13.2-14.0\% of $\mathrm{Pb}$ in ELVs estimated to be contained in ASR. As comparison to a previous study, Fuse et al. [20] estimated that 38,000 t-Pb were contained in ELVs generated as of 2005, but this included lead-acid batteries. If the $\mathrm{Pb}$ content in a lead-acid battery and in an ELV excluding the battery are assumed to be $7.9 \mathrm{~kg}-\mathrm{Pb}$ [21] and $1.85 \mathrm{~kg}-\mathrm{Pb}$, respectively (using reported the values reported by JAMA), the Pb content in ELVs excluding lead-acid batteries is estimated to be 7,200 t-Pb. Our estimate, which was in the range $7,200-7,700 \mathrm{t}-\mathrm{Pb}$ as of FY2005, was quite similar to this value.

\section{Pb content in ASR}

The estimated Pb content in ASR displayed in Fig. 6 (a) shows that even if there is no reduction, the $\mathrm{Pb}$ concentration may decrease. This is because the weight of the vehicle tends to get heavier compared with the past. As a result, the relative $\mathrm{Pb}$ content per vehicle decreases.

Fig. 6 (b) shows the Pb content in ASR compared to the case with no reductions. This indicates that it will take some time for the activities of car producers to reduce $\mathrm{Pb}$ content in vehicle components to have an effect, although both the minimum and maximum cases showed dramatic decreases in Pb content from FY1996 to FY2020. Approximately 5 years are needed to begin to reduce the $\mathrm{Pb}$ content in ASR. As of FY2010, a 14-23\% Pb reduction in ASR was estimated to have 
been achieved and this is expected to increase to 58-76\% by FY2020. However, ASR will continue to contain $240-420 \mathrm{mg}-\mathrm{Pb} / \mathrm{kg}$ in the future if the treatment system is not improved.

$\mathrm{Pb}$ content in ASR has been reported in some previous studies, as shown in Table 3. Pb content ranged from several hundred to several thousand ppm. However, the average value was generally under 3,000 ppm regardless of the region or time. The average value reported in Japan ranged between 920 and 2,700 ppm and our estimated values in Fig. 6 (a) fall into this range. ASR consists of various materials with different particle diameters. The fine ASR fraction generally contains the highest heavy metal concentrations [22] [23]. One of the difficulties of measuring the physical properties of ASR is how to obtain representative samples, as the composition of ASR depends on its pre-treatment such as dismantling and shredding.

\section{Uncertainties}

There are uncertainties in the estimation of ELVs generated, such as the future data reported by AIRIA being used as the number of vehicles first registered after FY2011. The number of sales will be affected by factors such as the market, lifestyle, and personal preferences. In addition, the assumed lifespan distribution was based on conventional vehicles. If the proportion of next-generation vehicles such as hybrid vehicles increases in the future, their lifespan may show different distributions.

We also have to clarify the substance flow of $\mathrm{Pb}$ after partitioning collected components, and recovering resources and ASR for the management of toxic substances. The ELV treatment stream was assumed to remain the same in the future. If collected components in the dismantling process and recovered resources in the shredding process are increased, the material flow of ELVs and substance flow of $\mathrm{Pb}$ contained in ELVs will change. For example, if more printed circuit board, which still contained Pb as of FY2010, could be collected separately in the dismantling or shredding process, the $\mathrm{Pb}$ content in ASR would decrease. Furthermore, we may be able to collect valuable substances contained in the printed circuit board.

This study focused only on the toxic substance, Pb, contained in a vehicle. Fuse et al. [40] estimated that 32,000 ton of $\mathrm{Pb}$ flowed through the international market as imported or exported used passenger vehicles in 2005, while the values were 3.4 million ton for ferrous materials, 310,000 ton for aluminium, and 75,000 ton for copper. They also estimated that 22,000 ton of manganese, 4,300 ton of nickel, 34,000 ton of chromium, and 1200 ton of molybdenum derived from engines exited Japan as used vehicles, used parts, and secondary materials between 1988 and 2005 [20]. Therefore, ELVs include both valuable and toxic substances, and with innovations in technology, vehicles contain increasing amounts of valuable substances. Thus, ELV management from such a viewpoint is also important, and we will study this in the future. 


\section{Conclusion}

ELVs must be treated properly as they contain toxic substances. The purpose of this study was to obtain useful information for ELV management from the viewpoint of toxicity. We focused on lead as a representative toxic substance contained in a vehicle and investigated the dynamic substance flow of lead contained in ELVs and its content in ASR after estimating the number of ELVs generated in the past, present, and future.

The annual number of ELVs generated was estimated to be 3.8 million as of FY2010 in Japan. The number decreased from FY2003 and was expected to be 2.9 million by FY2020. The effect of the reduction of $\mathrm{Pb}$ content in a vehicle and the lower number of vehicles in use could reduce the net amount of $\mathrm{Pb}$ contained in ELVs. However, the result also demonstrated that it is difficult to remove $\mathrm{Pb}$ completely. This is because 5,000-11,000 t-Pb will still remain in vehicles in use in FY2020 even though most components in new model vehicles could be replaced with lead-free alternatives. The substance flow as of FY2010 showed that Pb contained in ELVs accounted for 4,600-5,700 t-Pb. Of this, $13.2-14.0 \%$ or $650-749 \mathrm{t}-\mathrm{Pb}$ was estimated to be contained in ASR. Pb content in ASR could be dramatically decreased from FY1996 to FY2020, but ASR will continue to contain 240-420 $\mathrm{mg}-\mathrm{Pb} / \mathrm{kg}$ in the future if the treatment system is not improved.

This study focused only on $\mathrm{Pb}$ contained in a vehicle as a toxic substance. ELVs also contain some valuable substances, and in our next study, we will consider an ELV management system considering the amounts of both toxic and valuable substances based on elemental analysis and substance flow analysis.

Acknowledgements This work was supported by Environment Research and Technology Development Fund, Grant Number K123001, from the Ministry of the Environment, Japan. 


\section{References}

1. Japan Automobile Manufacturers Association, Inc. (JAMA) (2002) 2002 The motor industry of Japan. JAMA, Tokyo

2. Ministry of Economy, Trade and Industry, Japan (MITI) (1997) ELV recycling initiative

3. EU (2000) Directive 2000/53/EC of the European Parliament and the Council of 18 September 2000 on end-of-life vehicles -Commission Statement.

http://eur-lex.europa.eu/LexUriServ/LexUriServ.do?uri=CELEX:32000L0053:EN:NOT.

Accessed 06 September 2012

4. Kim S, Oguchi M, Yoshida A, and Terazono A (2012) Estimating the amount of WEEE generated in South Korea by using the population balance model. Waste Management, Online first

5. Polák M and Drápalová L (2012) Estimation of end of life mobile phones generation: the case study of the Czech Republic. Waste Management 32 (8): 1583-1591

6. Tasaki T, Takasuga T, Osako M, and Sakai S (2004) Substance flow analysis of brominated flame retardants and related compounds in waste TV sets in Japan. Waste Management 24 (6): $571-580$

7. Daigo I, Hashimoto S, Matsuno Y, and Adachi Y (2009) Material stocks and flows accounting for copper and copper-based alloys in Japan. Resources, Conservation and Recycling 53 (4): 208-217

8. Daigo I, Matsuno Y, and Adachi Y (2010) Substance flow analysis of chromium and nickel in the material flow of stainless steel in Japan. Resources, Conservation and Recycling 54 (11): 851-863

9. Tukker A, Buist H, van Oers L, and van der Voet E (2006) Risks to health and environment of the use of lead in products in the EU. Resources, Conservation and Recycling 49 (2): 89-109

10. Elshkaki A, van der Voet E, van Holderbeke M, and Timmermans V (2004) The environmental and economic consequences of the developments of lead stocks in the Dutch economic system. Resources, Conservation and Recycling 42(2): 133-154

11. Elshkaki A, van der Voet E, Van Holderbeke M, and Timmermans V (2009) Long-term consequences of non-intentional flows of substances: modelling non-intentional flows of lead in the Dutch economic system and evaluating their environmental consequences. Waste Management 29 (6): 1916-1928

12. Fuse M and Tsunemi K (2012) Assessment of the effects of the Japanese shift to lead-free solders and its impact on material substitution and environmental emissions by a dynamic material flow analysis. The Science of the Total Environment 438: 49-58

13. Automobile Inspection \& Registration Information Association (AIRIA) (2011) Vehicles in use of Japan FY2011 (in Japanese). AIRIA, Tokyo 
14. Light Motor Vehicle Inspection Organization (2011) Light motor vehicle in use of Japan (in Japanese). http://www.keikenkyo.or.jp/statistics/backnumber.html. Accessed 06 September 2012

15. Japan Automobile Dealers Association (JADA) (2009) Future sales of new vehicle prospect (in Japanese). JADA, Tokyo

16. Automobile Inspection \& Registration Information Association (AIRIA) (2011) Vehicles in use First registration year basis No. 39 (in Japanese). AIRIA, Tokyo

17. Automobile Inspection \& Registration Information Association (AIRIA) (2011) Vehicles in use Some classification basis No. 33 (in Japanese). AIRIA, Tokyo

18. Recycle One Inc. (2007) Report on the promotion of streamlining for ELV recycling (in Japanese).

19. Japan Automobile Manufacturers Association, Inc. (JAMA) Web Site (in Japanese). http://www.jama.or.jp/eco/asr_sw/. Accessed 1 Jun 2013

20. Fuse M, Nakajima K, and Yagita H (2007) Outflow of Resources from Japan focusing on End-of-life Vehicles. Materials Transactions 48 (9): 2436-2444

21. Hirai Y and Sakai S (2006) Material flow analysis of spent automotive batteries (in Japanese). Journal of the Japan Society of Waste Management Experts 17 (6): 404-415

22. Vermeulen I, Van Caneghem J, Block C, Baeyens J and Vandecasteele C (2011) Automotive shredder residue (ASR): reviewing its production from end-of-life vehicles (ELVs) and its recycling, energy or chemicals’ valorisation. Journal of Hazardous Materials 190 (1-3): 8-27

23. Morselli L, Santini A, Passarini F, and Vassura I (2010) Automotive shredder residue (ASR) characterization for a valuable management. Waste Management 30 (11): 2228-2234

24. Granata G, Moscardini E, Furlani G, Pagnanelli F, and Toro L (2011) Automobile shredded residue valorisation by hydrometallurgical metal recovery. Journal of Hazardous Materials 185 (1): 44-8

25. Santini A, Morselli L, Passarini F, Vassura I, Di Carlo S, and Bonino F (2011) End-of-Life Vehicles management: Italian material and energy recovery efficiency. Waste Management 31 (3): 489-494

26. Mancini G, Tamma R, and Viotti P (2010) Thermal process of fluff: preliminary tests on a full-scale treatment plant. Waste Management 30 (8-9): 1670-1682

27. Kameda T, Fukuda Y, Park Kye-Sung, Grause G and Yoshioka T (2009) Efficient dehalogenation of automobile shredder residue in $\mathrm{NaOH} /$ ethylene glycol using a ball mill. Chemosphere 74 (2): 287-292

28. Gonzalez-Fernandez O, Pessanha S, Queralt I and Carvalho M. L. (2009) Analysis of lead content in automotive shredder residue (ASR). Waste Management 29 (9): 2549-2552

29. Japan Environmental Sanitation Center (JESC) (2009) Report on the promotion of streamlining 
for ELV recycling (in Japanese)

30. Osada M, Tanigaki N, Takahashi S and Sakai S (2008) Brominated flame retardants and heavy metals in automobile shredder residue (ASR) and their behavior in the melting process. Journal of Material Cycles and Waste Management 10 (2): 93-101

31. Matsuto T, Nakajima S, Tojo Y, Kakuta Y and Matsuo T (2007) Characterization of Shredder Residues Derived from End-of-Life Vehicles and Home Electrical Appliances (in Japanese). Journal of the Japan Society of Waste Management Experts 18 (2): 126-136

32. Zolezzi M, Nicolella C, Ferrara S, Iacobucci C and Rovatti M (2004) Conventional and fast pyrolysis of automobile shredder residues (ASR). Waste Management 24 (7): 691-699

33. Gendebien A, Leavens A, Blackmore K, Godley A, Lewin K, Whiting K. J. and Davis R (2003) Refuse derived fuel, current practice and perspectives. Final Report for the European Commission - Directorate General Environment

34. Ministry of the Environment (2003) Report on the investigation of actual conditions of ELV

35. JESC (2002) Report on the investigation of actual conditions of ASR and waste oil from ELV (in Japanese)

36. Börjeson L, Löfvenius G, Hjelt M, Johansson S, and Marklund S (2000) Characterization of automotive shredder residues from two shredding facilities with different refining processes in Sweden. Waste Management \& Research 18 (4): 358-366

37. Trouvé G, Kauffmann A and Delfosse L (1998) Comparative thermodynamic and experimental study of some heavy metal behaviours during automotive shredder residues incineration. Waste Management 18 (5): 301-307

38. Saxena S. C., Rao N. S., Rehmat A and Mensinger M. C. (1995) Combustion and co-combustion of auto fluff. Energy 20 (9): 877-887

39. Sakai S, Ogawa M and Takatsuki H (1991) .Hazardous materials in shredder wastes and their appropriate treatment system (in Japanese). Journal of the Japan Society of Waste Management Experts 2 (2): 33-42

40. Fuse M, Nakajima K and Yagita H (2009) Global Flow of Metal Resources in the Used Automobile Trade. Materials Transactions 50 (4): 703-710 


\section{Figure captions}

Fig. 1 Image of estimation process

Fig. 2 Estimated results and statistical data of ELV generation between FY1990 and FY2020. Exported vehicles were included.

Fig. 3 Estimated amount of $\mathrm{Pb}$ in vehicles in Japan in FY1990-2020: (a) Minimum case, (b) Maximum case. $\mathrm{Pb}$ derived from lead-acid battery was excluded.

Fig. 4 Estimated partitioning of $\mathrm{Pb}$ for ELVs generated in FY2001-2011 (Minimum case). Pb derived from lead-acid batteries was excluded

Fig. 5 Substance flow of Pb for ELVs generated as of FY2010. Pb derived from lead-acid battery was excluded.

Fig. 6 (a) Estimated Pb content in ASR and (b) reduction of Pb content, compared to "No reduction case” between FY1990 and FY2020

Table $1 \mathrm{~Pb}$ contents in each component for every sales release year of a new model vehicle. $\mathrm{Pb}$ contents for each component as of 1996 were reported by JAMA.

Table 2 Partition ratios of $\mathrm{Pb}$ for each component

Table $3 \mathrm{~Pb}$ content in ASR reported in previous studies 


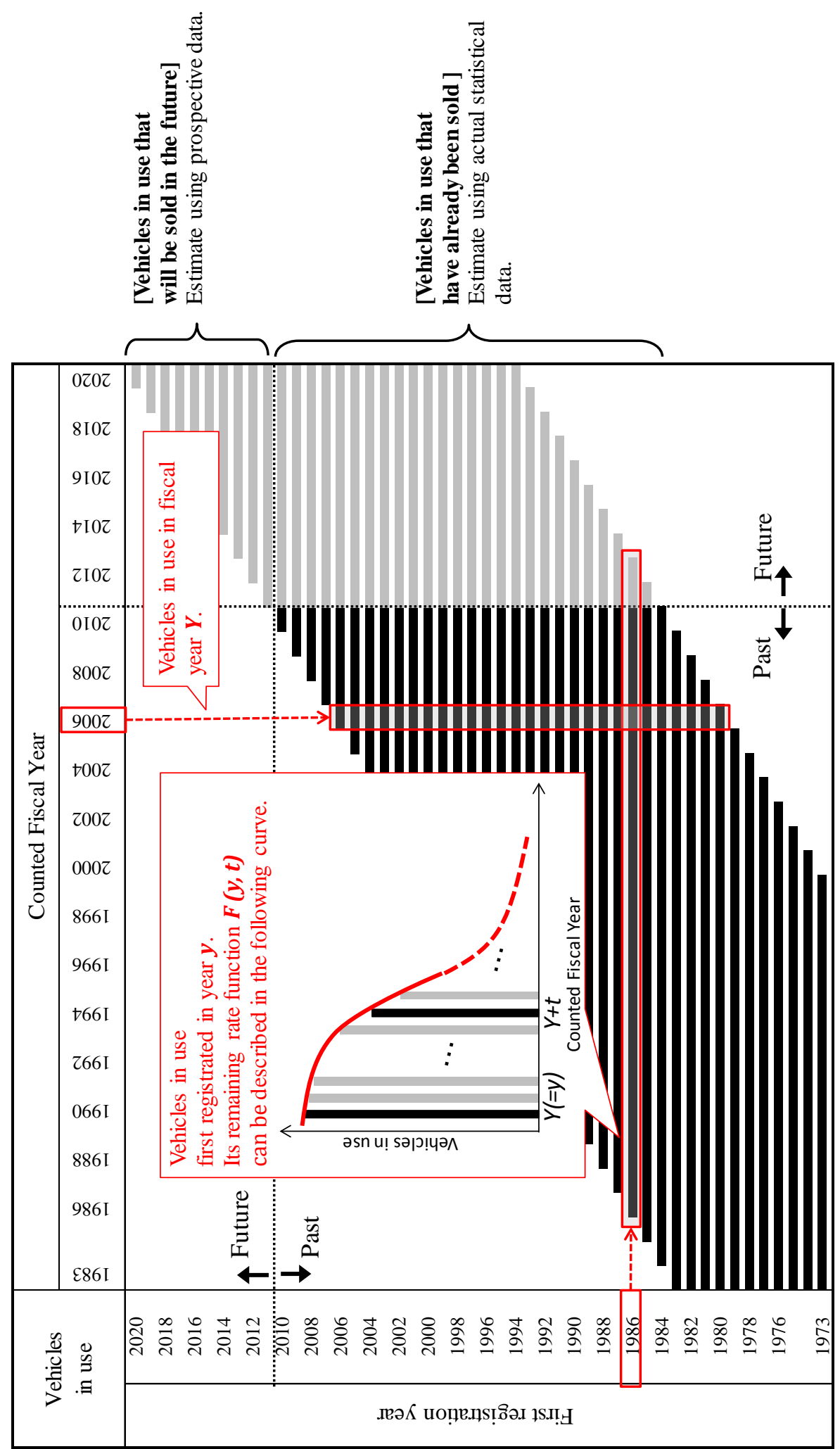

Fig. 1 Image of estimation process 


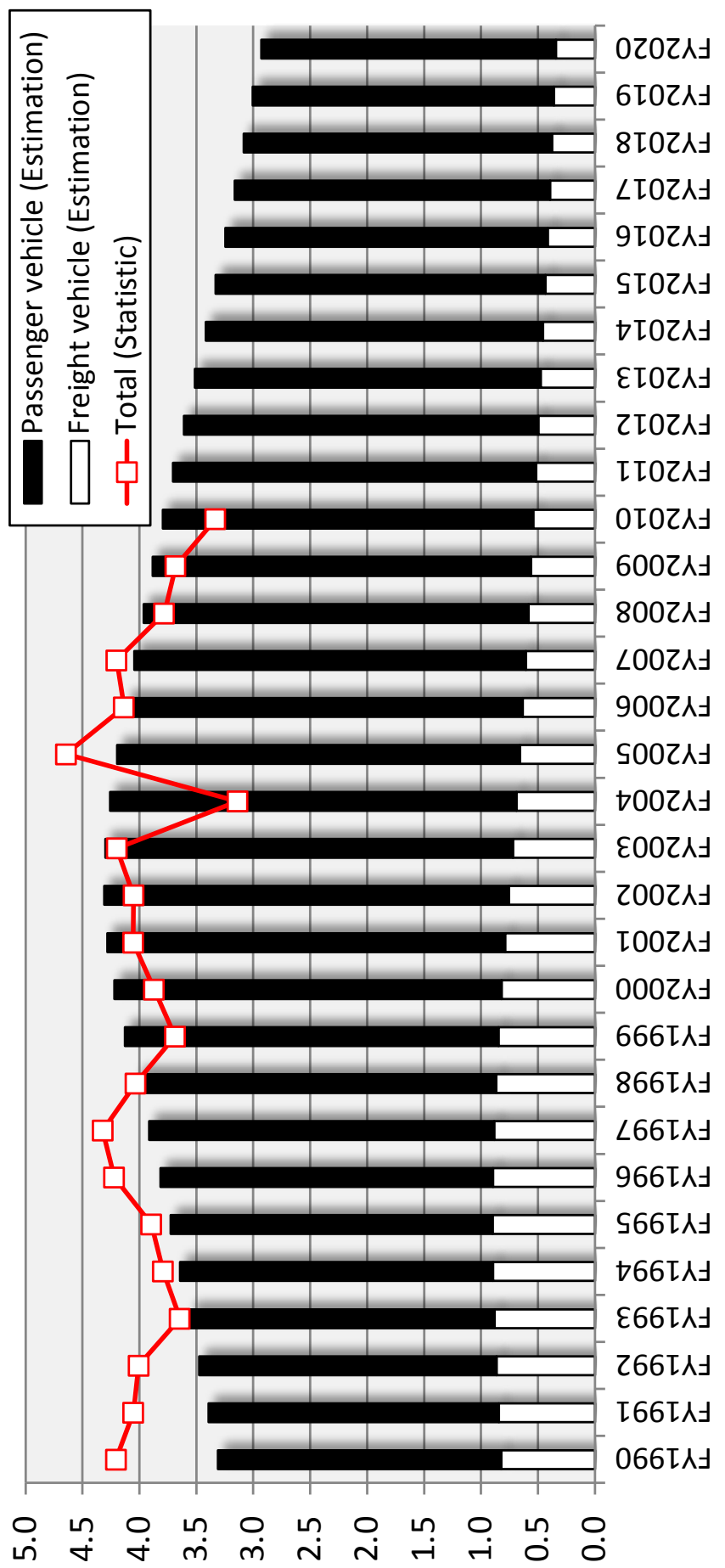

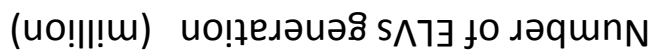

Fig. 2 Estimated results and statistical data of ELV generation between FY1990 and FY2020. Exported vehicles were included. 


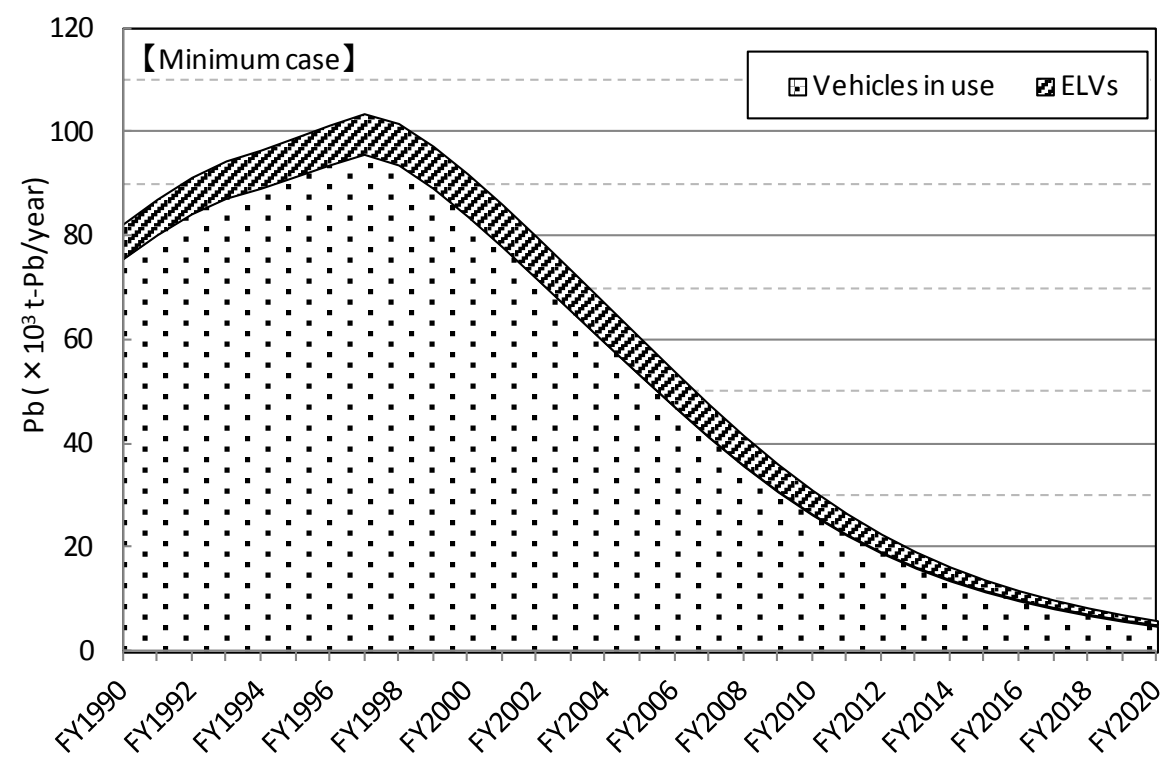

(a)

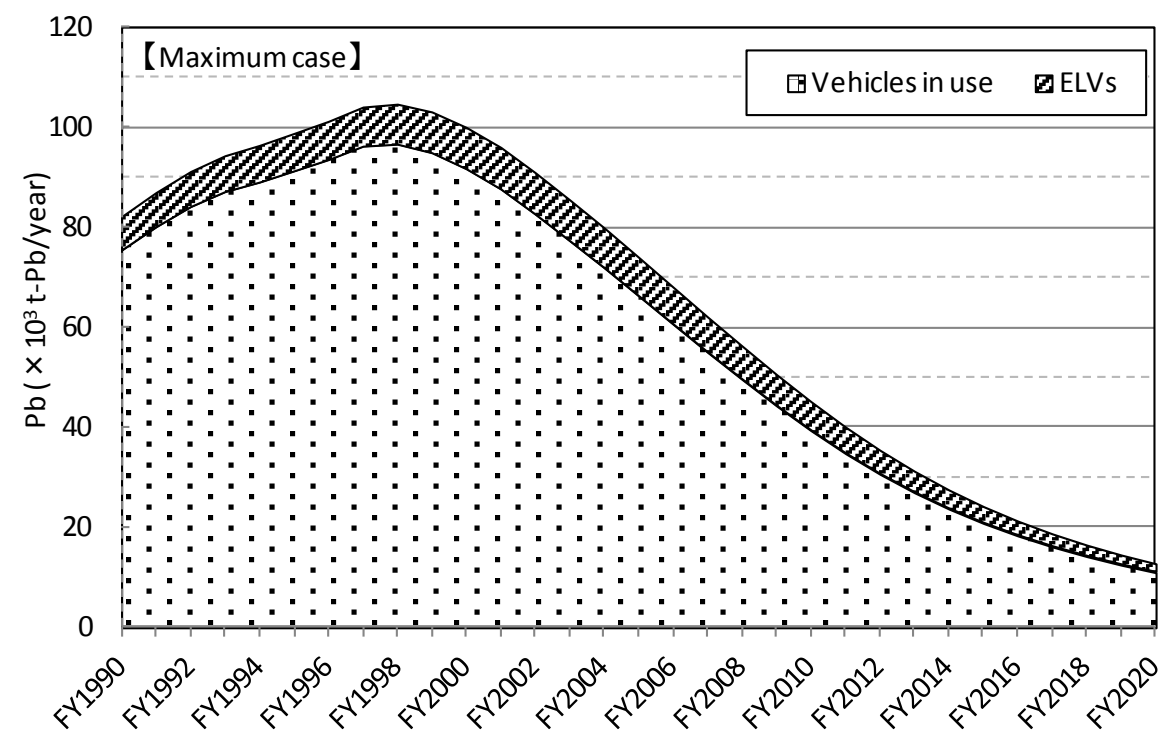

(b)

Fig. 3 Estimated amount of $\mathrm{Pb}$ in vehicles in Japan in FY1990-2020: (a) Minimum case, (b) Maximum case. $\mathrm{Pb}$ derived from lead-acid battery was excluded. 


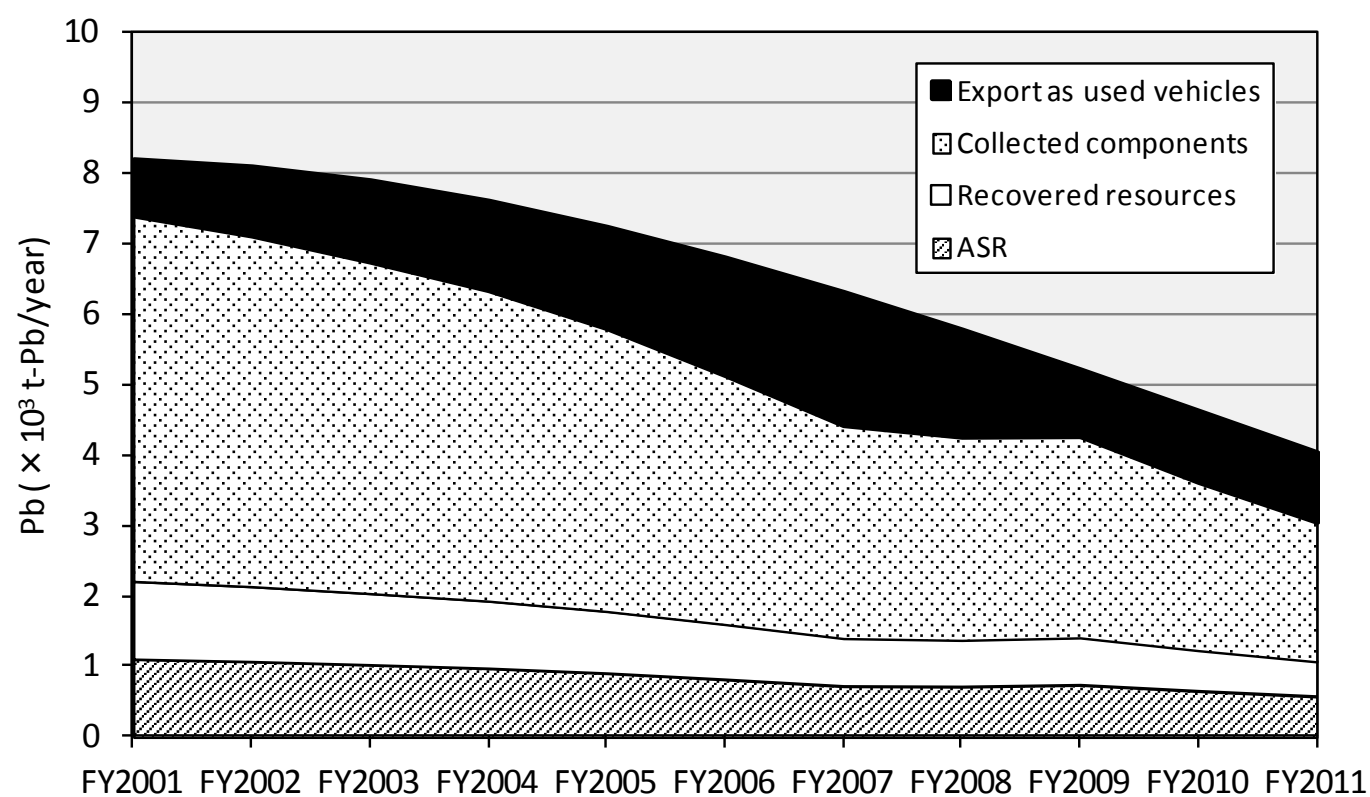

Fig. 4 Estimated partitioning of $\mathrm{Pb}$ for ELVs generated in FY2001-2011 (Minimum case). $\mathrm{Pb}$ derived from lead-acid batteries was excluded. 


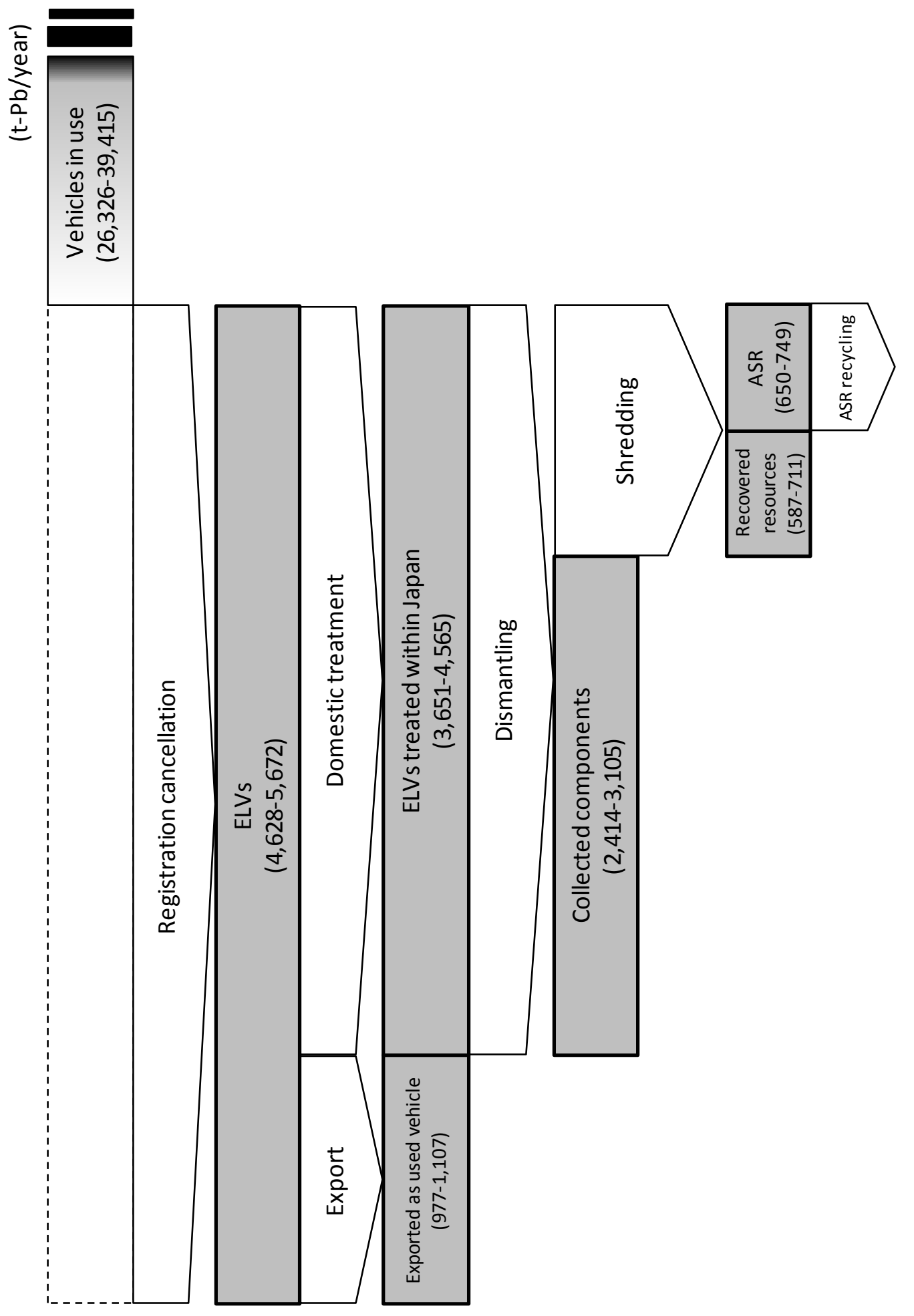

Fig. 5 Substance flow of Pb for ELVs generated as of FY2010. Pb derived from lead-acid battery was excluded. 


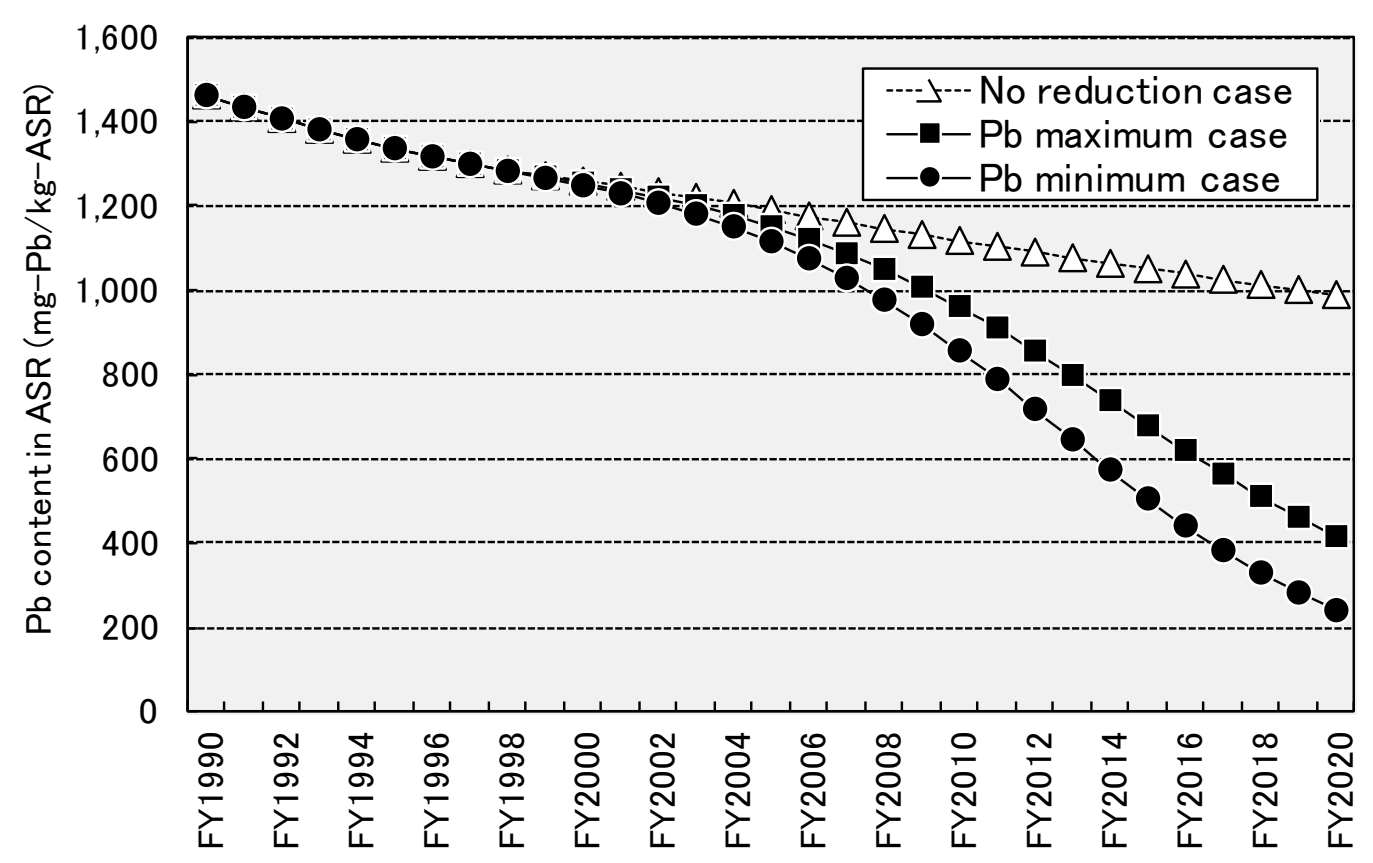

(a)

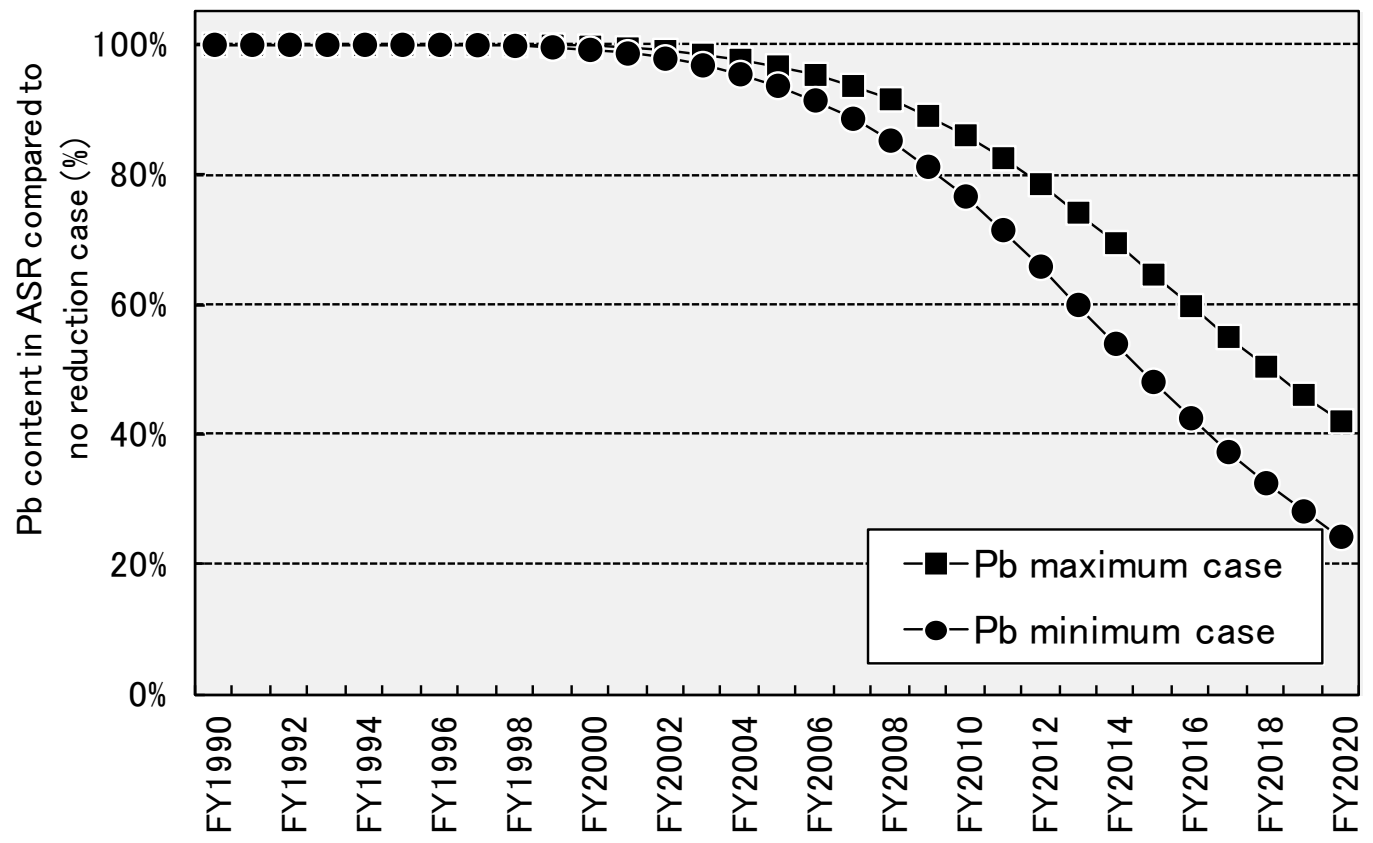

(b)

Fig. 6 (a) Estimated Pb content in ASR and (b) reduction of Pb content, compared to "No reduction case” between FY1990 and FY2020 
Table $1 \mathrm{~Pb}$ contents in each component for every sales release year of a new model vehicle. $\mathrm{Pb}$ contents for each component as of 1996 were reported by JAMA.

\begin{tabular}{|c|c|c|c|c|c|c|c|c|c|c|c|c|c|c|c|}
\hline \multirow[b]{2}{*}{ Components } & \multicolumn{15}{|c|}{ Sales release year of a new model vehicle } \\
\hline & 1996 & 1997 & 1998 & 1999 & 2000 & 2001 & 2002 & 2003 & 2004 & 2005 & 2006 & 2007 & 2008 & 2009 & 2010 \\
\hline Copper radiator & 580 & 290 & 0 & 0 & 0 & 0 & 0 & 0 & 0 & 0 & 0 & 0 & 0 & 0 & 0 \\
\hline Battery cable terminal & 290 & 218 & 145 & 73 & 0 & 0 & 0 & 0 & 0 & 0 & 0 & 0 & 0 & 0 & 0 \\
\hline Wheel balancer & 240 & 240 & 213 & 187 & 160 & 133 & 107 & 80 & 53 & 27 & 0 & 0 & 0 & 0 & 0 \\
\hline Fuel tank & 200 & 180 & 160 & 140 & 120 & 100 & 80 & 60 & 40 & 20 & 0 & 0 & 0 & 0 & 0 \\
\hline Heat core & 110 & 0 & 0 & 0 & 0 & 0 & 0 & 0 & 0 & 0 & 0 & 0 & 0 & 0 & 0 \\
\hline Harness & 90 & 77 & 64 & 51 & 39 & 26 & 13 & 0 & 0 & 0 & 0 & 0 & 0 & 0 & 0 \\
\hline Electrodeposition & 50 & 50 & 50 & 44 & 38 & 31 & 25 & 19 & 13 & 6 & 0 & 0 & 0 & 0 & 0 \\
\hline Printed circuit board & 50 & 50 & 50 & 50 & 50 & 50 & 50 & 50 & 50 & 47 & 45 & 42 & 37 & 45 & 35 \\
\hline Under coating & 20 & 15 & 10 & 5 & 0 & 0 & 0 & 0 & 0 & 0 & 0 & 0 & 0 & 0 & 0 \\
\hline Fuel hose & 20 & 16 & 12 & 8 & 4 & 0 & 0 & 0 & 0 & 0 & 0 & 0 & 0 & 0 & 0 \\
\hline Seatbelt Gsensor & 20 & 15 & 10 & 5 & 0 & 0 & 0 & 0 & 0 & 0 & 0 & 0 & 0 & 0 & 0 \\
\hline Glass-ceramic & 15 & 13 & 10 & 8 & 5 & 3 & 0 & 0 & 0 & 0 & 0 & 0 & 0 & 0 & 0 \\
\hline Side protection mold & 10 & 8 & 5 & 3 & 0 & 0 & 0 & 0 & 0 & 0 & 0 & 0 & 0 & 0 & 0 \\
\hline Power steering hose & 5 & 5 & 4 & 3 & 1 & 0 & 0 & 0 & 0 & 0 & 0 & 0 & 0 & 0 & 0 \\
\hline Other engine component & 100 & 100 & 100 & 100 & 100 & 100 & 100 & 100 & 100 & 81 & 61 & 42 & 37 & 45 & 35 \\
\hline \begin{tabular}{|l|} 
Other car component \\
\end{tabular} & 50 & 50 & 50 & 50 & 50 & 50 & 45 & 40 & 34 & 29 & 24 & 19 & 16 & 20 & 16 \\
\hline Total & 1,850 & 1,327 & 883 & 727 & 567 & 493 & 420 & 349 & 290 & 210 & 130 & 103 & 91 & 111 & 86 \\
\hline
\end{tabular}


Table 2 Partition ratios of $\mathrm{Pb}$ for each component

\begin{tabular}{|c|c|c|c|c|c|c|}
\hline \multirow{3}{*}{ Components } & \multicolumn{6}{|c|}{ Partition ratio of $\mathrm{Pb}$ (Assumption) } \\
\hline & \multicolumn{2}{|c|}{ Dismantling } & \multicolumn{2}{|c|}{ Shredding } & \multicolumn{2}{|c|}{ ASR treatment } \\
\hline & \multicolumn{2}{|c|}{ Components collected } & \multicolumn{2}{|c|}{ Recovered resources } & \multicolumn{2}{|c|}{ ASR } \\
\hline Copper radiator & $99.6 \%$ & (A) & $0.4 \%$ & (B) & $0.0 \%$ & (E) \\
\hline Battery cable terminal & $69.6 \%$ & (A) & $30.4 \%$ & (B) & $0.0 \%$ & (E) \\
\hline Wheel balancer & $49.3 \%$ & (A) & $0.0 \%$ & $(\mathrm{E})$ & $50.7 \%$ & (C) \\
\hline Fuel tank & $78.2 \%$ & (A) & $21.8 \%$ & (B) & $0.0 \%$ & $(\mathrm{E})$ \\
\hline Heat core & $69.9 \%$ & (A) & $30.1 \%$ & (B) & $0.0 \%$ & $(\mathrm{E})$ \\
\hline Harness & $77.6 \%$ & (A) & $11.2 \%$ & (D) & $11.2 \%$ & (D) \\
\hline Electrodeposition & $0.0 \%$ & $(\mathrm{E})$ & $50.0 \%$ & (D) & $50.0 \%$ & (D) \\
\hline Printed circuit board & $0.0 \%$ & $(\mathrm{E})$ & $50.0 \%$ & (D) & $50.0 \%$ & (D) \\
\hline Under coating & $0.0 \%$ & (E) & $50.0 \%$ & (D) & $50.0 \%$ & (D) \\
\hline Fuel hose & $21.8 \%$ & (A) & $0.0 \%$ & (E) & $78.2 \%$ & (C) \\
\hline Seatbelt G sensor & $0.0 \%$ & $(\mathrm{E})$ & $50.0 \%$ & (D) & $50.0 \%$ & (D) \\
\hline Glass-ceramic & $13.8 \%$ & (A) & $0.0 \%$ & $(\mathrm{E})$ & $86.2 \%$ & (C) \\
\hline Side protection mold & $0.0 \%$ & $(\mathrm{E})$ & $0.0 \%$ & $(\mathrm{E})$ & $100.0 \%$ & (C) \\
\hline Power steering hose & $27.5 \%$ & (A) & $0.0 \%$ & (E) & $72.5 \%$ & (C) \\
\hline Other engine component & $96.0 \%$ & (A) & $4.0 \%$ & (B) & $0.0 \%$ & (E) \\
\hline Other car component & $0.0 \%$ & $(\mathrm{E})$ & $50.0 \%$ & (D) & $50.0 \%$ & (D) \\
\hline
\end{tabular}

A: Data from previous study [18]

B: Assuming that all remaining component is recovered after component collection in dismantling process

C: Assuming that all remaining component is disposed of after component collection in dismantling process

D: Assuming a 50:50 ratio

E: Assuming zero 
Table $3 \mathrm{~Pb}$ content in ASR reported in previous studies

\begin{tabular}{|c|c|c|c|c|c|c|c|}
\hline \multirow{2}{*}{ Authors } & \multirow{2}{*}{ NoS } & \multicolumn{2}{|c|}{$\mathrm{Pb}$ content [mg/kg] } & \multirow{2}{*}{ Country } & \multirow{2}{*}{$\begin{array}{c}\text { Sampling } \\
\text { Year }\end{array}$} & \multirow{2}{*}{ Remarks } & \multirow{2}{*}{ Ref. } \\
\hline & & Min-Max & Average & & & & \\
\hline Granata et al. (2011) & 1 & $1,030-5,100$ & 2,300 & Italy & - & \begin{tabular}{|l|}
1 sample with \\
4 particle diameters \\
\end{tabular} & [24] \\
\hline Santini et al. (2011) & 3 & $442-600$ & 510 & Italy & - & Car fluff (light ASR) & {$[25]$} \\
\hline Mancini et al. (2010) & 3 & $2,088-2,322$ & 2,205 & Italy & 2006 & & {$[26]$} \\
\hline Morselli et al. (2010) & 1 & $2,000-5,000$ & 4,000 & Italy & - & \begin{tabular}{|l|}
1 sample with \\
4 particle diameters \\
\end{tabular} & {$[23]$} \\
\hline Kameda et al. (2009) & 1 & - & 1,400 & Japan & - & & [27] \\
\hline $\begin{array}{l}\text { Gonzalez-Fernandez } \\
\text { et al. (2009) }\end{array}$ & 4 & $4,600-11,600$ & 7,508 & Spain & $\begin{array}{l}2005- \\
2006 \\
\end{array}$ & \begin{tabular}{|l|}
1 sample with \\
6 particle diameters \\
\end{tabular} & [28] \\
\hline JESC (2009) & 2 & $1,400-2,200$ & 1,800 & Japan & 2009 & & [29] \\
\hline Osada et al. (2008) & 1 & - & 1700 & Japan & - & & [30] \\
\hline Matsuto et al. (2007) & $4^{* 1}$ & $532-1,850$ & 1,338 & Japan & 2003 & & [31] \\
\hline Recycle One. Inc.(2007) & 2 & - & 1,800 & Japan & - & & [18] \\
\hline Zolezzi et al. (2004) & 1 & - & 2,000 & Italy & - & & [32] \\
\hline Gendebien et al. (2003) & 1 & - & 2,710 & EU & - & & [33] \\
\hline $\begin{array}{l}\text { Ministry of the } \\
\text { Environment, Japan } \\
(2003)\end{array}$ & 2 & $640-1,600$ & 1,120 & Japan & 2003 & & [34] \\
\hline JESC (2002) & 4 & $490-1,200$ & 920 & Japan & 2002 & & [35] \\
\hline Börjeson et al. (2000) & $7^{* 1}$ & $4,050-12,200$ & 6,983 & Sweden & - & $\begin{array}{l}\text { Plant, dismantling } \\
\text { level, type of vehicle } \\
\text { are different }\end{array}$ & {$[36]$} \\
\hline Trouvé et al. (1998) & 5 & - & 1,400 & France & - & & [37] \\
\hline Saxena et al. (1995) & 1 & - & 200 & USA & - & \begin{tabular}{|l|} 
Moisture content of \\
$40.2 \%$ \\
\end{tabular} & [38] \\
\hline Sakai et al. (1991) & 3 & $1,300-4,800$ & 2,700 & Japan & - & & [39] \\
\hline
\end{tabular}

NoS: Number of Samples, Ref.: Reference, *1: Only ASRs were counted 